\title{
Understanding and Undermining the Growth Paradigm-CORRIGENDUM
}

\author{
CHRISTOPHER NOWLIN
}

https://doi.org/10.1017/S0012217317000555, Published by Cambridge University Press, 5 September 2017.

Keywords: Arendt, Galbraith, economics, growth, permaculture, sharing, unemployment, corrigendum

The title of the citation listed in footnote 87 of (Nowlin, 2017) was incorrectly spelled. It should have instead appeared as, "Krantz, "Shmita Revolution: The Reclamation and Reinvention of the Sabbatical Year," at 4 of 31". In addition, the reference should have appeared as follows,

Krantz, David 2016 "Shmita Revolution: The Reclamation and Reinvention of the Sabbatical Year," in 7 Religions 100; available at http:/www.mdpi.com/2077-1444/ 7/8/100/htm. Accessed on July 31, 2017.

Finally, "shmita" was also misspelled in the sentence at the top of page 575 as "schmita." The correct sentence should read "the Toraic concept of shmita..."

We sincerely regret the error and any problems that have resulted for the authors and readers.

\section{Reference}

Nowlin, Christoper

2017 "Understanding and Undermining the Growth Paradigm." Dialogue 56 (3): 559-593.

Dialogue 56 (2017), 611.

(C) Canadian Philosophical Association/Association canadienne de philosophie 2017 doi:10.1017/S001221731700083X 